\title{
EDQM-HC Combined Pack Terminology
}

National Cancer Institute

\section{Source}

National Cancer Institute. EDQM-HC Combined Pack Terminology. NCI Thesaurus. Code C150106.

Terminology subset about single terms to describe two or more medicinal products that are packaged together and marketed under a sing le license, and which are intended to be administered independently, as separate pharmaceutical products. 